\title{
Comportamento estratégico da cadeia produtiva do peixe na região de Dourados, MS, Brasil
}

\author{
Strategic behaviour of the fish's productive chain in Dourados, MS, Brazil
}

\author{
André Ximenes de Melo ${ }^{[a]}$, Renato Luiz Sproesser ${ }^{[\mathrm{b}]}$, Patrícia Campeão ${ }^{[\mathrm{c}]}$
}

[a] Mestre em Agronegócios pela Universidade Federal de Mato Grosso do Sul, professor da Universidade do Estado de Mato Grosso (UNEMAT), Tangará da Serra, MT - Brasil, e-mail: msc.andreximenes@gmail.com

[b] Pós-Doutor pela Ecole Nationale des Ingenieurs et Techniques de Industries Agroalimentaires, professor associado da Universidade Federal de Mato Grosso do Sul, Campo Grande, MS - Brasil, e-mail: drls@nin.ufms.br

[c] Doutora em Engenharia de Produção pela Universidade Federal de São Carlos, professora adjunta da Universidade Federal de Mato Grosso do Sul, Campo Grande, MS - Brasil, e-mail: campeao@nin.ufms.br

\section{Resumo}

Este paper tem a finalidade de questionar se, numa cadeia produtiva, "a maioria das empresas só é bemsucedida se outras também forem". Para tal, utilizou-se o método de estudo de caso calcado em pesquisa tipo survey e documental, com análise de dados primários, na região de Dourados, MS, no ano de 2008. Observou-se que a falta de planejamento e de gestão das diversas atividades que compõem a cadeia produtiva do peixe, e especialmente da piscicultura, tem se desenvolvido com problemas estratégicos. A engorda de peixes tem características de concorrência perfeita: o produto é homogêneo e o preço é dado pelo comprador. A produção de alevinos se aproxima mais de um oligopólio diferenciado, em que a estratégia dominante é a diferenciação dos produtos: Dourado, Pacu, Pintado e Tambacu. Alguns players preferem produzir espécies nativas e usam essa flexibilidade para introduzir espécies exóticas. A diferenciação também se dá em duas dimensões: alevinos de baixo custo e com alto potencial de filetagem. Já o segmento de frigorificação caracteriza-se como oligopólio concentrado. O frigorífico pesquisado atua com escala produtiva, distribuindo para varejistas e para exportação. A sua maior diferenciação está na espécie nativa produzida e em seus cortes especiais. A estratégia predominante no abate/frigorificação é a diferenciação do produto, buscando oferecer produtos considerados superiores. Em síntese, observou-se que os elos de alevinagem e frigorificação têm base na estratégia da diferenciação enquanto os engordadores atuam numa estrutura de mercado análoga à de concorrência perfeita.

Palavras-chave: Competitividade. Vantagem competitiva. Estratégia. 


\begin{abstract}
This paper aims to question if in a production chain, "most companies is successful only if others also are". For this reason we used the case study method based on a survey and documentary research with primary data analysis, in Dourados, MS, in 2008. It was observed that the lack of planning and managing of the various activities that make up the production chain of the fish, especially fish farming has developed with strategic problems. The fattening of fish has characteristics of perfect competition: the product is homogeneous and the price is given by the buyer. The fry production looks more as a kind of oligopoly where the dominant strategy is the product variety: Golden, Pacu, Pintado and Tambacu. Some players prefer to produce native species and use this flexibility to introduce exotic species. The difference also occurs in two dimensions: low cost fries and high potential for filleting. But the cold storage segment is characterized as a concentrated oligopoly. The analyzed cold storage operates with a production scale distributing to and exportation. Its biggest difference is in the production of native species and their special cuts. The prevailing strategy in the slaughter/refrigeration is the differentiation in the product aiming to offer products considered superior. In summary it was noted that the nursery and cold storage links are based on the strategy of differentiation while fatteners act in a market structure analogous to perfect competition.
\end{abstract}

Keywords: Competitiveness. Competitive advantage. Strategy.

\section{Introdução}

A aquicultura brasileira atualmente conta com seis grupos principais de produção de organismos aquáticos em cativeiro, representando $80 \%$ de toda a produção aquícola em águas doces e salgadas, são eles: camarões marinhos, camarões de água doce (pitú), mexilhões, ostras, rãs e peixes de água doce (ROSA, 2001).

Os peixes no Pantanal são abundantes, diversificados, possuem larga distribuição geográfica e são muito utilizados na alimentação local como fonte de proteína. As espécies nativas têm carne com textura, cor e sabor apreciados por todos que as conhecem, seu consumo está sendo estimulado em virtude do baixo nível de colesterol em relação às carnes vermelhas, principalmente a bovina. A pesca, esportiva e profissional, é a segunda maior atividade econômica do Pantanal, movimentando cerca de $\mathrm{R} \$ 150$ milhões/ano. Esse setor da piscicultura apresentou crescimento, pois os pesque-pague, ou pesqueiros, se multiplicaram rapidamente nos últimos anos (MORAES et al., 2007).

No Estado do Mato Grosso do Sul, a piscicultura é uma atividade relativamente nova, existe pouca informação sobre a produção, a industrialização e a comercialização relacionada a essa atividade e seu sistema produtivo conta com inúmeros projetos, porém, tem se desenvolvido de forma desordenada. A região de Dourados foi a escolhida pelo fato de possuir o maior número de piscicultores e por ser responsável, entre 2001 e 2002, por aproximadamente $62 \%$ da produção do Estado e porque a cadeia produtiva da piscicultura no Estado tem se desenvolvido basicamente com investimentos do setor produtivo.

\section{Metodologia}

O presente estudo foi de natureza aplicada, com objetivo exploratório/descritivo e sua estratégia de abordagem foi baseada na técnica survey, pois houve a intenção de testar uma teoria e as relações causais, assim como estabelecer a existência de relações causais, e também se a relação existe, identificar os conceitos e buscar descobrir novas possibilidades e dimensões da população de interesse. Estabeleceu-se como propósito verificar se a percepção dos fatos está ou não de acordo com a realidade. O processo de amostragem foi composto pelos associados da cooperativa, ou seja, todos os associados, oferecendo o número necessário para que os resultados obtidos fossem precisos e confiáveis. Um dos instrumentos utilizados para a realização do survey foi o questionário, tendo como estratégia de aplicação a entrevista pessoal. A amostra não probabilística foi obtida por conveniência (convenience), os participantes foram escolhidos por estarem arrolados na cooperativa e também porbola de neve (snowball), pois os participantes iniciais indicaram os que estavam próximos do pesquisador. A abrangência, nesse sentido, envolve os associados da cooperativa da cidade de Dourados, MS, em: 4 
alevinadores e 17 produtores (engordadores) baseados nos seguintes municípios: Deodápolis, Douradina, Dourados, Itaporã (também o único frigorífico), Maracaju, Nova Andradina e Nova Alvorada do Sul. A pesquisa ocorreu no outono de 2008.

\section{Revisão teórica}

O presente trabalho visa a esclarecer a dinâmica dos sistemas e sua funcionalidade, seus elos, seus valores, suas diferenças e o entendimento sobre a vantagem competitiva, os sistemas locais de produção, a cadeia de valores e as estratégias genéricas, tendo como objeto de estudo a cadeia da piscicultura na região de Dourados, MS.

Nos agrupamentos de empresas, Hamel (1998) destaca que, em aglomerações espaciais e setoriais, existem redes de relacionamento que resultam na aquisição de alguma vantagem competitiva para as empresas e, consequentemente, para o grupo como um todo. Nesses espaços, as empresas estão procurando atender mais rápido aos desejos dos clientes, melhorar a qualidade e conquistar mais pontos de market share no mercado, o que significa menores custos fixos e maiores chances de competitividade. A dinâmica das cadeias agroindustriais, da forma que conceitua Rosa (2001), está fortemente condicionada pelas estratégias de concorrência e crescimento das empresas processadoras de alimentos. Além de ocupar uma posição estratégica dentro da cadeia, a indústria alimentar tem missão de codificar os desejos e as necessidades do consumidor, traduzindo-os em novas oportunidades de investimento para si própria e transmitindo-os para seus fornecedores mais distantes, que pouco percebem o cliente final.

Uma nova forma de organizar e coordenar os agentes de uma cadeia de suprimentos passa a ser vista como inovação organizacional, ou seja, uma forma inovadora de se organizarem e se relacionarem. Não são os acordos e parcerias firmados entre os agentes, e nem mesmo a própria coordenação da cadeia de suprimentos, que devem ser vistos como uma inovação em si, essa inovação ocorre a partir do momento em que a cadeia de suprimentos passa a ser considerada e coordenada como uma grande empresa e, para poder competir, deve agir como tal, tendo na inovação a sua vantagem competitiva, pois, nesse caso, o que está em jogo é o desempenho de um sistema e não de uma firma individual (FURLANETTO, 2002).
Ocorre que os sistemas são formados por segmentos que podem exibir diferentes graus de dependência mútua. Essa dependência está determinada pelos atributos das transações intersegmentos, em especial pela especificidade dos ativos envolvidos nas transações (locacionais, temporais, tecnológicas, etc.).

Se as especificidades são assimétricas, os conflitos são prováveis, especialmente quanto à avaliação de políticas públicas setoriais. Quando se estende o conceito de competitividade das empresas para os sistemas, admite-se que o segmento como um todo seja capaz de sobreviver no mercado, ainda que várias de suas firmas não o sejam e que os segmentos de um determinado sistema possam apresentar graus distintos de competitividade e, portanto, possa acontecer de um ou mais segmentos de um sistema nacional ou regional reduzir sua participação relativa nos mercados, sendo substituído por importações. A depender das especificidades dos ativos envolvidos nas transações entre os segmentos, podem se formar sistemas regionais que irão competir entre si nos mercados consumidores nacionais ou internacionais, gozando de níveis diferenciados de competitividade. Como o desempenho do sistema depende não de uma firma, mas de firmas que se dependem mutuamente, ocasionam dessa forma as transações locacionais, criando facilidade de se negociar entre os agentes, pelas garantias intrínsecas, pelo fácil acesso aos produtores, técnicas, treinamentos e outros (PORTER, 1989).

Nas considerações de Porter (1989), durante milhares de anos as vantagens competitivas das organizações e até mesmo das nações resumiam-se à disponibilidade de fatores físicos, tais como mão de obra, matéria-prima e capital. A partir da Revolução Industrial, esses parâmetros de competitividade sofreram grandes mudanças, a tecnologia e informação foram incorporadas, acreditando Haddad (2003) que os fundamentos da competitividade moderna residem no desenvolvimento científico e tecnológico incorporado às organizações públicas e privadas. Nesse sentido, a sustentabilidade de um cluster produtivo tem muito mais a ver com a qualidade do capital humano e intelectual, que comanda cada uma das suas atividades, do que com eventos efêmeros de natureza macroeconômica ou de políticas regionais que podem gerar competitividades espúrias. As novas tecnologias, ao disseminarem-se pela sociedade, possibilitam a criação de novos desejos, necessidades e oportunidades nos indivíduos. 
O desenvolvimento regional deve envolver os conceitos de "endogenia regional" e de "sustentabilidade ambiental", assim Campeão e Sproesser (2000) nos fazem crer que a busca por competitividade tem tido predominância nas discussões atuais. As organizações, quer sejam privadas ou públicas, estão cada vez mais se sentindo forçadas a alterar suas estratégias, com vistas a melhorar seus desempenhos e, assim, sobreviver num ambiente altamente dinâmico e competitivo. Assim, define-se competitividade como a capacidade de produzir bens e serviços que passem no teste de competição internacional, enquanto os cidadãos desfrutam de um padrão de vida cada vez melhor e mais sustentável. As condições de competitividade dos negócios têm dependido da capacidade das empresas de agregar valor aos seus produtos, não mais nos ganhos de escala, passando a oferecer produtos especiais voltados a segmentos específicos de mercado. Esse fato é extremamente crítico quando o produto é uma commoditye, portanto, altamente padronizado, oferecido em alta escala, o que lhe confere um valor unitário diminuído no mercado e um baixo poder competitivo.

A empresa precisa dominar uma ou mais atividades que se identifiquem como vantagem competitiva efetiva, a fim de que o sucesso competitivo venha a ser atingido. Porter (1989) diz que isso pode decorrer de custos mais baixos na capacidade de destacar a empresa junto aos consumidores, pois sustentar a vantagem competitiva pode-se traduzir como elevação da produtividade, já que está associada à melhoria da qualidade e eficiência no processo produtivo. A conceituação de competitividade acarreta consequências para a determinação dos indicadores de desempenho, com o aumento da participação no mercado, que é um indicador de resultado. Produtividade e custos são indicadores de eficiência que esclarecem a competitividade. Kupfer (1991) conceitua a competitividade sob duas óticas:

1) competitividade como desempenho; e

2) competitividade como eficiência, que, sob essa ótica, é ligada à capacidade de uma empresa na produção de bens com maior eficiência que os seus concorrentes e é dada pelo nível de capacitação apreendida pelas empresas.

A natureza da competição não é o equilíbrio, mas um constante estado de mudanças, o que levou
Porter (1989) a afirmar que a melhoria e inovação numa indústria são processos que não terminam nunca, e que as vantagens são logo superadas ou anuladas. É esse ambiente, com ameaças e oportunidades, que impõe aos empresários uma série de desafios. A empresa deve ser capaz de se transformar sempre que necessário; isso se dá muito mais por pressão dos concorrentes e consumidores que por vontade própria das empresas, que estão constantemente buscando (e encontrando) soluções inovadoras.

Porter (1989) e Rosa (2001) afirmam que uma empresa cria valor para o comprador reduzindo seu custo ou elevando o desempenho. O custo é importante não somente para as empresas que pretendem competir em preço, como também para aquelas que concorrem num dos campos da diferenciação, como produto ou imagem; assim as organizações podem utilizar suas Vantagens Competitivas, que na visão de Prahalad e Hamel (1990), por meio de core competences, ou com o mapa das inovações, devem dispor de barreiras para que não sejam facilmente copiadas. Criar, manter e sustentar uma vantagem competitiva é garantir desempenho superior, considerando ainda como a capacidade organizacional de combinar, misturar e integrar recursos em produtos e serviços.

As pesquisas de Porter $(1980,1989)$ estão voltadas para as questões que, segundo ele, são as determinantes da competitividade. A primeira questão é como determinar a atratividade de um ramo de negócio, pois oferece oportunidades diferentes de rentabilidade, inerente a um ramo que é um ingrediente essencial na determinação da rentabilidade de qualquer empresa que atue nele. A base fundamental do desempenho acima da média, em longo prazo, é a vantagem competitiva sustentável. Embora uma empresa possa ter inúmeros pontos fortes e pontos fracos em comparação com seus concorrentes, esse modelo pretende encontrar os fatores que determinam a atratividade de um negócio ou indústria, e o melhor posicionamento de uma empresa dentro de um mercado, e como os fatores e forças competitivas vão interferir na escolha da estratégia da organização, que pode escolher entre três posições estratégicas chamadas de genéricas, que são: custo, diferenciação e enfoque.

A estratégia da liderança, em custo, exige que a organização se molde para oferecer o menor custo total a seus clientes. Já a estratégia de diferenciação busca oferecer um diferencial aos clientes, por meio das dimensões estratégicas (qualidade intrínseca, 
serviço, inovação, tecnologia, marketing, etc.); por sua vez, o enfoque será buscado em um nicho específico de mercado, visando a atendê-lo de forma única e muito superior aos demais competidores.

A escolha de uma estratégia genérica por uma organização ou unidade de negócio não garante a operacionalização, mas garante que a organização poderá buscar diferenciação em vários fatores como atendimento, confiabilidade de entrega, flexibilidade, tecnologia, inovação, etc.; ou seja, as empresas podem optar por duas estratégias básicas: competir por diferenciação de produto ou por liderança de custos.

A liderança nos custos é conseguida por meio da estratégia orientada para esse objetivo básico e implica produzir em larga escala, de forma padronizada, com preços baixos, dando destaque à tecnologia de processo (escala), utilizando-se de um conjunto de políticas funcionais, e não apenas ações isoladas, é a ferramenta para empresas que não conseguem se diferenciar pela qualidade ou atributos extrínsecos ao produto, tal que a diminuição dos custos se torna um diferencial que eleva a empresa a ser uma das líderes de mercado, não só pelos preços, mas também pela lucratividade. Autores como Shank e Govindarajan (1997), baseados em Porter (1989), trabalham com propósito de análise dos custos.

As atividades devem ser separadas para a análise dos custos, caso representem um percentual significativo ou rápido crescimento dos custos operacionais ou dos ativos, e devem ser identificadas, principalmente os grandes componentes de seu custo. Fica evidente que a liderança no custo, a mais clara e mais perceptível das três estratégias genéricas, para a amplitude da empresa, normalmente é importante para sua vantagem escolhida. As fontes de vantagem de custo variam e dependem da estrutura da indústria (PORTER, 1989).

Se uma empresa pode alcançar e sustentara liderança no custo total, então ela será um competidor acima da média em sua indústria, desde que possa comandar os preços na média da indústria ou perto dela, com preços equivalentes ou mais baixos do que seus rivais. A posição de baixo custo de um líder traduz-se em retornos mais altos, um líder em custo não pode ignorar as bases da diferenciação. Se o seu produto não é considerado comparável ou aceitável pelos compradores, um líder de custo será forçado a reduzir os preços bem abaixo dos da concorrência para ganhar vendas, o que pode anular os benefícios de sua posição de custo. Essa estratégia faz com que a empresa tenha retornos acima da média em seu setor e se defenda contra a rivalidade dos concorrentes e dos compradores poderosos, e muitos planos estratégicos estabelecem a "liderança de custo" ou a "redução de custo" como meta (PORTER, 1989; PAULA; BIGNET'TI, 2002; MELO, 2008).

$\mathrm{Na}$ análise dos direcionadores de custo (condutores de custo), o foco está em compreender quais os fatores que causam o custo internamente. Esse conceito pode ser entendido no escopo do ABC - Custeio Baseado em Atividades. A efetiva gestão de custos deve ser realizada sobre as causas dos custos - a aprendizagem que aumenta a eficiência e faz o custo de uma atividade de valor cair com o passar do tempo - e, da mesma forma que com economias de escala, sem dúvidas o índice de aprendizagem está ligado ao volume cumulativo nessa atividade; bem como o aprimoramento da comunidade à medida que ela venha aprender com o sistema. O índice de aprendizagem está quase sempre sujeito a retornos decrescentes e, portanto, ele pode declinar no decorrer do tempo para algumas atividades de valor com o amadurecimento de uma empresa (MARINHO, 1999; SHANK; GOVINDARAJAN, 1997; PORTER, 1989).

Investir em tecnologia para direcionar os condutores de custos a favor da organização envolve uma política de custos, com um custeio profissional e responsável. A avaliação correta dos custos, a mensuração e classificação são atributos indispensáveis, bem como as ferramentas que auxiliam o seu entendimento no campo da estratégia empresarial, como a Cadeia de Valor, que busca interpretar a origem e orientar as soluções, baseando-se na inter-relação entre os diversos condutores de custo. Nesse caso as economias de escala, procedimentos otimizados como aquisição e o monitoramento cuidadoso dos custos unitários e totais, se tornam fundamentais.

A diferenciação implica produzir sob encomenda ou com flexibilidade, com ênfase na tecnologia de produto com o intuito de tornar o produto ou o serviço oferecido pela empresa diferente, criando algo que seja considerado único no âmbito de toda a indústria. Essa meta é alcançada quando há lealdade do consumidor à marca ou quando o produto não é sensível aos preços, o que garante o fator estratégico de retornos acima da média de mercado. Esse tipo de estratégia dificulta o alcance de grandes parcelas de mercado. A diferenciação provém da criação singular de valor para o comprador (MELO et al., 2010). 
Nesse tipo de estratégia, a empresa procura ser única, ao longo de algumas dimensões amplamente valorizadas pelos compradores, seleciona um ou mais atributos, que muitos compradores (indústria) consideram importantes, posicionandose singularmente para satisfazer tais necessidades. Assim é recompensada pela sua diferenciação com um preço-prêmio, a lógica da diferenciação exige de uma empresa a escolha de atributos que sejam diferentes de seus rivais, ser uma empresa verdadeiramente única, ou ser considerada única para que possa esperar um preço-prêmio.

A proximidade na diferenciação significa que o desconto de preço necessário para obter uma parcela de mercado aceitável não compensa a vantagem de custo de um líder no custo e, portanto, esse líder no custo obtém retornos acima da média. Ainda deve ser considerada a lealdade do comprador durante quedas cíclicas ou sazonais e o ponto-chave para a diferenciação é a aquisição de uma vantagem que seja rapidamente percebida pelo consumidor. Os meios para a diferenciação são específicos para cada indústria e eles podem estar baseados em características intrínsecas ao produto, à imagem da marca, aos serviços agregados, ao sistema de entrega, à qualidade e/ou à tecnologia. A diferenciação de um produto é criar algo que seja diferente aos olhos do consumidor, podendo também ser baseada no sistema de entrega pelo qual o produto é vendido.

A diferenciação de uma empresa em uma atividade de valor é determinada por uma série de condutores básicos, análogos aos condutores dos custos; porém, são essas as razões subjacentes pelas quais uma atividade é singular. Sem executá-los, uma empresa não pode desenvolver inteiramente meios para a criação de novas formas de diferenciação, ou para identificar o grau de sustentabilidade da diferenciação existente. As estratégias de liderança no custo e $n a$ diferenciação buscam a vantagem competitiva em um limite amplo de segmentos industriais, enquanto a estratégia do enfoque visa a uma vantagem de custo (enfoque no custo) ou uma diferenciação (enfoque na diferenciação) num segmento mais estreito. No enfoque em custo, uma empresa procura uma vantagem de custo em seu segmento-alvo; enquanto no enfoque na diferenciação uma empresa busca a diferenciação em seu segmento-alvo. Ambas as variantes da estratégia de enfoque baseiam-se em diferenças entre os segmentos-alvo de um enfocador e outros segmentos na indústria. $\mathrm{O}$ enfoque estreito por si só não é suficiente para um desempenho acima da média (PORTER, 1989).

$\mathrm{Na}$ "cadeia de valor" (value chain), numa visão revolucionária da organização empresarial para a época que, basicamente, desagrega a organização em atividades estrategicamente relevantes e passíveis de mensuração, enquanto Davenport ${ }^{1}$ (1994) apresenta uma das definições mais populares na literatura sobre o assunto, conceituando processo como um conjunto estruturado e mensurável de atividades projetadas para produzir uma saída específica para um mercado ou consumidor particular, o processo empresarial pode ser entendido como um conjunto de atividades com uma ou mais espécies de entrada e que cria uma saída de valor para o cliente. O conceito de Cadeia de Valor, de uma forma geral, é um conjunto de atividades que são executadas para projetar, produzir, comercializar, entregar e sustentar um determinado produto ou serviço. A empresa obterá vantagens competitivas e estará inserida em uma corrente maior de atividades denominada de Sistema de Valores se executar essas atividades a um custo menor ou de forma melhor do que a concorrência.

O uso desse conceito estabelece uma forma sistemática de avaliação de todas as atividades executadas por uma empresa e do modo como elas interagem entre si, bem como das inter-relações entre diferentes cadeias de valores de diferentes empresas pertencentes a um mesmo sistema de valores, o que inclui fornecedores que propiciam insumos, passando pelos canais de distribuição até atingir o cliente final. A cadeia de valor de uma empresa, portanto, além de traduzir-se na sua verdadeira fonte de vantagem competitiva, permite a desejada ampliação da "visão gerencial" para além dos domínios da organização (BRAND, 2004; MARINHO, 1999; PORTER, 1989).

Shank e Govindarajan (1997) descrevem que a análise da cadeia de valor é relevante para todas as empresas, pois é a forma mais significativa de explorar a vantagem competitiva. Esses autores ressaltam que a análise da cadeia de valor é essencial para determinar onde exatamente existem oportunidades para melhorar o desempenho empresarial de

1 DAVENPORT, T. H. Reengenharia de processos. Rio de Janeiro: Campus, 1994.. 
forma durável. Conforme Franco (2005), um fator relevante é que, mesmo as empresas sendo similares, a cadeia de valor é única para cada organização.

\section{Apresentação e discussão dos resultados}

A estrutura de mercado identificada na região em relação à produção dos alevinos foi o oligopólio concentrado. Identificou-se a presença de quatro. A estratégia dominante nessa estrutura de mercado é a diferenciação dos produtores oferecidos, pois produzem algo preferido ou especial, e que podem cobrar mais por isso.

Os altos custos dos alevinadores com os principais itens de custeio como: mão de obra, energia (energia elétrica e combustível), matrizes e manutenção, deveriam ter controle rigoroso em suas análises; pois podem vir a ter prejuízos com facilidade. Porém não sabem diferenciar entre custos fixos e variáveis, ou seja, não têm controle técnico de seus custos. A formação do alevinador tem suma importância na pesquisa e desenvolvimento de hibridismos e na educação alimentar dos alevinos. Na região está evidente que o aprendizado estratégico tem início com o esclarecimento da visão compartilhada que o alevinador tenta alcançar. A ênfase na construção de relações de causa e efeito gera um raciocínio sistêmico dinâmico, permitindo que os indivíduos, nos diversos setores, compreendam suas funções e inter-relações, como o seu papel influencia o papel de outras pessoas/empresas; além de facilitar a definição de desempenho e as iniciativas correlatas que não apenas medem a mudança, como também a alimentam.

Novas visões passaram a ser consideradas importantes, como: valor futuro, capital intelectual, inovação, aprendizagem organizacional, tecnologia e logística. Isso pode incluir melhoria nas formas de atendimento, melhores programas de produção, aumento da eficiência da mão de obra, modificações no produto (hibridismo), peixes com possibilidades de oferecer melhor rendimento por carcaça, utilização da matéria-prima e uso de ativos. As perspectivas de aprendizado e crescimento enfatizam a importância de alinhar os ativos intangíveis essenciais à implantação da estratégia que se destacam na região, são eles: Capital Humano - competências estratégicas (habilidades, talento e know-how); Capital de Informaçãoinformações estratégicas (sistemas, bancos de dados, bibliotecas e redes); Capital Organizacional-cultura, liderança, alinhamento e trabalho em equipe (a capacidade dos alevinadores de mobilizar e sustentar o processo de mudança necessário para executar a estratégia) com a estratégia dos alevinadores.

Percebe-se que existe cooperação interorganizacional que caracteriza uma importante estratégia para que os alevinocultores aumentem sua eficiência e seu poder de competitividade, pois mesmo que trabalhem com um portfólio limitado de produtos podem se apoiar nos concorrentes quando ocorrem pedidos de alevinos que não se desenvolvem. Essa é uma das formas de relações intra e interempresas na região, não existindo o fator cooperacional para vendas de alevinos.

Os alevinadores acreditam que a melhor produção se dá sempre com múltiplas espécies, cada alevinador tem em sua estrutura a produção de no mínimo dez espécies. Foram encontradas 21 espécies diferentes de alevinos. A diferença de preço praticado entre eles é o resultado do processo de diferenciação empreendido pelos alevinadores. Tal diferenciação permite cobrar um preço-prêmio quando é "percebida" pelo comprador, o que se dá de diversas formas, tais como: engorda linear, crescimento rápido, potencial de carcaça e potencial de briga. Existe ainda um mix de produtos em que não há concorrência direta, visto que são ofertados por alevinadores distintos.

O sistema de diferenciação usado pelos alevinadores se dá por meio do atendimento das necessidades em duas dimensões - a atual e a futura. A necessidade atual é de alevinos com valores mais baixos que a média na tabela; já nos alevinadores que estão se preparando para o futuro, os alevinos chegam a ter valores até 5 vezes maior que o preço médio. Essa percepção nos propõe três tipos alevinos:

1) alevinos básicos: custam menos de $\mathrm{R} \$$ 1,00 por unidade - a concorrência é maior e o produto é competitivo, são eles: Cachara, Carpa Capim, Paqui - ou Tambacu, Piracanjuba, Pirapitinga;

2) alevinos intermediários: entre $\mathrm{R} \$ 1,00 \mathrm{e}$ $\mathrm{R} \$ 6,99 . \mathrm{Na}$ fase adulta são peixes de porte avantajado, mas que não são comercialmente procurados, porém possuem grande potencial de carnes. Seu tamanho, em idade adulta, é de mais de 30 quilos. São eles: Jurupensen, Pintado e Cachara; 
3) alevinos compotencial para o futuro: que custam acima da média, entre $\mathrm{R} \$ 7,00$ até $\mathrm{R} \$ 45,00$ a unidade. São peixes mais procurados pelo valor comercial, potencial palatável e pela capacidade de produzir carnes, bem como pelo rendimento médio de carcaça, que pode chegar a $65 \%$, são basicamente: Cachapira - (cachara $X$ pirarara) e a Pirarara, que podem chegar a mais de 1,5 metro de comprimento e 50 quilos; o Pirarucu pode crescer até quatro metros de comprimento e pesar cerca de $250 \mathrm{~kg}$.

Há a necessidade de produzir peixes de pequeno tamanho para servirem de aproveitadores de restos alimentares (detritívoros) e servirem também de complementos alimentares para os peixes carnívoros/ peixívoros, que dará economicidade na criação. Num segundo plano, produzir peixes de boa qualidade e sabor, mas que sejam aproveitados também pela sua esportividade ao serem capturados, o que pode fazer a alegria dos frequentadores de pesqueiros.

Os engordadores, não tendo recursos necessários para investir em novas tecnologias, se aproveitam de capacidade produtiva dos alevinocultores e tornam-se competidores por meio do preço, ao utilizar a estrutura dos quatro alevinadores que trabalham com a venda de larvas a baixíssimos custos, satisfazendo a necessidade de trabalharem baseados em custos. No que tange a esse fato, Rosa (2001) destaca a importância da cooperação e rivalidade, afirmando a necessidade da cooperação na área tecnológica para ganhar eficiência e competitividade. Essa dimensão traz no seu bojo o conflito latente entre concorrência e cooperação, que, muitas vezes, é ignorado nos estudos de competitividade. No entanto, é crescente o reconhecimento de que a coordenação e cooperação tanto vertical quanto horizontal são importantes na vitalidade da concorrência.

A engorda de peixes na atual estrutura de mercado tem características de concorrência perfeita, pois há um grande número de engordadores. O produto é homogêneo, o preço é dado pelo comprador e predomina baixo grau de cooperação. Nesse caso, a estratégia é a dominação pelos custos, não havendo diferenciação nos produtos disponibilizados, sendo os produtos homogêneos entre os engordadores, a margem é fortemente condicionada pela estrutura de custos de produção e, nesse sentido, o insumo que mais tem capacidade de diminuir os custos de produção é a ração comercial, que se dá pela participação da ração nos custos do piscicultor. Estudos como "custos na produção intensiva de surubins em gaiolas" (COELHO; CYRINO, 2006) afirmam que a participação dos gastos com ração é em torno de $21 \%$, resultados dissonantes com diversos autores que mostram que a ração representa de $60 \%$ a $70 \%$ dos custos em sistemas intensivos de criação (COELHO; CYRINO, 2006; MARTIN et al., 1995; SCORVO FILHO; MARTIN; AYROZA, 1998). Esses dados demonstram que mesmo os pesquisadores da piscicultura não chegam a valores próximos uns dos outros, e que esta não concordância élatente no setor de engorda, onde os engordadores não dominam seus custos e se deparam com as dificuldades iniciais na preparação das informações entre custos fixos e variáveis. A lâmina d'água ideal para a piscicultura situa-se próximo de 11 hectares. A maioria dos engordadores não tem essa quantidade de lâmina d'água. O que pode estar acarretando prejuízos ainda não identificados. A atividade requer volumes expressivos para a diluição dos custos fixos.

Quatro tipos distintos de engordadores foram encontrados. São eles:

1) engordadorfamiliar: possui, com 7 hectares de lâmina d'água, trabalho exclusivamente executado pela família, dependendo basicamente da piscicultura;

2) pequeno engordador: usa a família e empregados e lâmina d'água de 2 hectares, o que equivale a $5,40 \%$ de sua propriedade, preferindo vender para pesqueiros e ao consumidor em vendas especiais de Natal e Páscoa;

3) médio engordador: com 6,25 hectares de lâmina d'água. A fazenda é tocada pela família, com mão de obra assalariada, preferindo vender para pesqueiros, seu peixe sai vivo e pode fornecer diversas espécies, obtendo maior valor nas vendas; e

4) grande engordador (ou o profissional): possui 65 hectares de lâmina d'água. São fazendas gerenciadas por profissionais qualificados, trabalham com contratos de fornecimento para o frigorífico, caracterizando uma propriedade que produz em série, vende em larga escala. 
A ração de alta qualidade diminui o tempo de engorda, ou seja, a utilização de rações comerciais desenvolve com igualdade um lote de peixes e de forma rápida, característica do conceito dynamic technical efficiency, que leva em conta o fato de que uma redução de custos produtivos exige algum gasto prévio que se traduz, em sua maior parte, nos custos fixos para os engordadores.

Os engordadores acreditam produzir algo preferido ou mais especial e que podem cobrar mais por isso. Levam em consideração os supermercados (os peixes de couro, principalmente os pintados, são os mais procurados por cadeias varejistas), porém os pesqueiros são os clientes mais desejados, pois compram o ano todo com aumento do fluxo na época da piracema, em que o prazer da diversão é o maior influenciador no preço do produto. Os peixes mais procurados nesses estabelecimentos são os de pesca esportiva, que conferem certa dificuldade ao serem retirados do lago; e aqueles que têm sabor mais apreciado na região, dentre eles destacam-se: o Pacu, o Piauçu, o Pintado e a Tilápia.

O frigorífico pesquisado trabalha focado na distribuição de Surubim-Pintado para grandes redes de supermercados e duas lojas específicas de peixe que usam a marca. Acredita ser, esse frigorífico, o único produtor global dessa espécie, o que permite perceber agregação de valor, para ser percebido pelo consumidor. Vejamos o caso do filé que acompanha parte da pele que acaba sendo um autenticador de veracidade. Optou-se pela integração vertical a montante e à jusante. A integração vertical age no sentido de ampliar os benefícios gerados pelo sistema como um todo e, portanto, maior competitividade do seu produto à jusante; a integração vertical garante o padrão de qualidade ao longo de todo o processo produtivo.

A estratégia predominante nessa estrutura de mercado é a diferenciação do produto, via mix, qualidade e imagem: oferecer produtos considerados superiores gera a necessidade de ampliação da qualidade na quantidade de filé aproveitável e, por sua vez, as condições de trabalho favorecem a importância do aprendizado. O pagamento de preço-prêmio ao produtor que fornece matéria-prima com carcaça que produza maior quantidade de filé (por unidade/ peso) começa a ser difundido no setor. Isso poderá ser benéfico à atividade de engorda, dentre elas, à elevação geral do padrão de qualidade do segmento e ao estabelecimento de condutores que melhor definam os atributos transacionados.
A pesquisa demonstra as evidências dos condutores de diferenciação, na área de abate e frigorificação, destacada pela diversidade do mix dos produtos, da utilização da aprendizagem, tanto nas formas estratégicas quanto nas operacionais, nas inter-relações com os elos, na integração vertical, na inovação tecnológica e nas marcas dos produtos.

\section{Considerações finais}

O presente estudo buscou conhecere avaliar o conjunto de reações observáveis nas ações dos players resultantes da experiência individual e coletiva existente. Não se considerou, neste estudo, a opinião preconcebida ou difundida entre a coletividade da região estudada. É importante notar que os elos da cadeia do peixe da região são diferenciados durante toda a cadeia. A pesquisa buscou analisar apenas os três mais relevantes elos, sendo especificados da seguinte forma: a alevinocultura, a engorda e o abate com a frigorificação.

A estrutura de mercado identificada na região, em relação à produção dos alevinos, foi o oligopólio concentrado. Cada produtor tem nichos específicos com os quais tem mais habilidades. A estratégia dominante nessa estrutura de mercado é a diferenciação dos produtos oferecidos, num mix de 58 produtos composto de diferentes alevinos. Apenas quatro espécies são comuns aos alevinocultores: Dourado, Pacu, Pintado e Tambacu. Os alevinadores produzem espécies nativas e usam a flexibilidade para introduzir espécies exóticas já aclimatadas e prontas para a engorda. Eles utilizam, ainda, a diferença de preço como resultado do processo de diferenciação, o que demonstra a busca da singularidade em algo valioso para os compradores. A diferenciação se dá em duas dimensões das necessidades, com alevinos de baixo custo e com pesquisas e desenvolvimento de alevinos com alto potencial de filetagem, o que permite identificar três formas diferentes de atingir o mercado: os alevinos de baixo valor, a menos de $\mathrm{R} \$ 1,00$ por unidade, tendo a concorrência é maior; os de preços intermediários, entre $\mathrm{R} \$ 1,00$ e $\mathrm{R} \$ 6,99$ a unidade; e os peixes de linha, com tendência de futuro com preços acima da média, entre $\mathrm{R} \$ 7,00 \mathrm{e}$ $\mathrm{R} \$ 45,00$. A unidade de alevino, porém, ainda não é comercialmente aceita e requer longo tempo de criação (maior tempo indica maior fluxo de caixa e maior risco). 
Os alevinocultores não reconhecem sua competitividade vista como desempenho expresso na participação no mercado (market share), ou seja, sua participação no mercado, assim como a posição econômica e a taxa de lucratividade medida por índices, não é fator que interessa ao alevinocultor.

A engorda de peixes na atual estrutura de mercado tem características de concorrência perfeita, pois há um grande número de engordadores. O produto é homogêneo (o produtor não recebe um valor adicional ao fornecer um produto de melhorqualidade), o preço é dado pelo compradore, assim, a estratégia é a dominação pelos custos, não havendo diferenciação nos produtos disponibilizados. A participação da ração nos custos do piscicultor torna alta a margem e fortemente condicionada pela estrutura de custos de produção. Nesse sentido, o insumo que mais tem capacidade de diminuir os custos de produção é a ração comercial, que tem sua qualidade percebida quando diminui o tempo de engorda e proporciona crescimento equânime. Esse é o conceito de dynamic technical efficiency, que leva em conta o fato de que uma redução de custos produtivos exige algum gasto prévio. A pesquisa identificou quatro tipos: o familiar, o pequeno, o médio e o grande, que é considerado engordador profissional.

O mix de produtos oferecidos pelos engordadores fica entre duas e cinco diferentes espécies de peixes: os mais comercializados são o Pintado (indústria e supermercados), o Pacu e o Tambaqui (supermercados e pesqueiros), o "Cat Fish" e a Piraputanga (pesqueiros). Quem procura atender uma dessas linhas tem que dispor sempre do produto e isso exige múltiplos tanques. Quando se trata de pesqueiros, além de ter vários tanques para idades diferenciadas, é necessário um mix maior.
A pesquisa demonstra que os objetivos como retorno sobre o investimento e valor econômico agregado podem oferecer medidas globais de resultados de sucesso das estratégias financeiras destinadas a aumentar a receita, reduzir custos e aumentar a utilização do ativo, não sendo conhecidos ou sendo desconsiderados.

O segmento de frigorificação caracteriza-se como oligopólio concentrado. O frigorífico pesquisado atua com escala produtiva, distribuindo para varejo e exportação. Acredita-se que sua maior diferenciação está na espécie nativa produzida e em seus cortes especiais. A empresa busca a coordenação para o montante e a jusante da cadeia, para que possa suprir sua demanda de peixe e garantir a qualidade necessária, além de diminuir seus custos de produção. A estratégia predominante no abate/ frigorificação é a diferenciação do produto, via mix, qualidade e imagem. Os funcionários são treinados com frequência para oferecer produtos considerados superiores (diferenciação do produto).

Não basta incentivar o aumento da produção sem fortalecer os canais de escoamento que passam pela diversificação das formas de apresentação dos produtos, pelos investimentos em marketing e pela valorização do consumidor final.

Estratégias começam a ser mais claramente definidas, especialmente na alevinagem e no abate/ frigorificação. As estruturas adotadas buscam aumentar o valor agregado pela cadeia produtiva conforme dispõe a Tabela 1.

O efeito da marca como fato de diferenciação está presente não só na marca empresarial, mas no diferencial do produto, sendo o próprio peixe "Pintado", carne de boa aparência e bom sabor.

Tabela 1 - Condutores de diferenciação no abate/frigorificação

\begin{tabular}{llll}
\hline & Alevinagem & Engorda & Abate/frigorificação \\
\hline Estrutura predominante & Diferenciação & Dominação pelos custos & Diferenciação \\
Estratégia predominante & Oligopólio concentrado & Concorrência perfeita & Oligopólio concentrado \\
$\begin{array}{l}\text { Principais condutores } \\
\text { estratégicos }\end{array}$ & $\begin{array}{l}\text { Inovação tecnológica } \\
\text { orientada para o aumento da } \\
\text { produtividade; aprendizagem; } \\
\text { mix de produtos; qualidade. }\end{array}$ & $\begin{array}{l}\text { Grande número de } \\
\text { engordadores; clientes. }\end{array}$ & $\begin{array}{l}\text { Inovação tecnológica } \\
\text { orientada para o aumento } \\
\text { do mix; mix de produtos; } \\
\text { qualidade. }\end{array}$ \\
\hline
\end{tabular}

Fonte: INSTITUTO, 2006. 


\section{Referências}

BRAND, F. C. Sistemáticas de apoio ao processo de decisão quanto à terceirização no contexto de umacadeiaprodutiva: o caso da cadeia eletroeletrônica gaúcha. 2004. 206 f. Dissertação (Mestrado em Engenharia da Produção) - Universidade Federal do Rio Grande do Sul, Porto Alegre, 2004.

CAMPEÃO, P.; SPROESSER, R. L. Competitividade e desenvolvimento regional: conceitos e definições. Revista de Economia e Administração, Campo Grande, n. 2, p. $62-70,2000$.

COELHO, S. R. C.; CYRINO, J. E. P. Custos na produção intensiva de surubins em gaiolas. Informações Econômicas, São Paulo, v. 36, n. 4, p. 38-51, 2006.

DAVENPORT, T. H. Reengenharia de processos. 2. ed. Rio de Janeiro: Campus, 1994.

FRANCO, R. G. P. Metodologia para implantação da gestão por processos em empresas do setor metal-mecânico. 2005. 100 f. Dissertação (Mestrado em Engenharia de Produção) - Universidade Federal de Santa Catarina, Florianópolis, 2005.

FURLANETTO, E. L. Formação das estruturas de coordenação nas cadeias de suprimentos: estudos de caso em cinco empresas gaúchas. 2002. 292 f. Tese (Doutorado em Administração) - Universidade Federal de Rio Grande do Sul, Porto Alegre, 2002.

HADDAD, P. R. Cluster e desenvolvimento endógeno. 2. ed. Belo Horizonte: UFMG, 2003.

HAMEL, G. Dez princípios de revolução. HSM Management, São Paulo, v. 1, n. 6, p. 55-69, 1998.

KUPFER, D. Padrões de concorrência e competitividade. 2. ed. Rio de Janeiro: UFRJ/IEI, 1991.

MARINHO, S. V. Utilização do conceito de gestão estratégica de custos dentro do balanced scorecard. 1999. 150 f. Dissertação (Mestrado em Engenharia da Produção) Universidade Federal de Santa Catarina, Florianópolis, 1999.

MARTIN, N. B. et al. Custos e retornos na piscicultura em São Paulo. Informações Econômicas, São Paulo, v. 25 , n. 5, p. 9-47, 1995.

MELO, A.X. Comportamento estratégico dos agentes produtivos da cadeia produtiva do peixe na região de Dourados - MS. 2008. 120 f. Dissertação (Mestrado em Agronegócios) - Universidade Federal de Mato Grosso do Sul, Campo Grande, 2008.
MELO, A. X. et al. A estratégia de dominação pelos custos na piscicultura sul-mato-grossense: o caso da região de Dourados/MS. Revista Brasileira de Gestão e Desenvolvimento Regional, Taubaté, v. 6, n. 1, p. 2-21, 2010.

MORAES, A. S. et al. Pesquisa, meio ambiente e produção no Pantanal. 2. ed. Corumbá: Embrapa, 2007.

PAULA, E. W.; BIGNETTI, L. P. Estudo sobre as práticas de inovação e as estratégias adotadas por empreendedores de alta tecnologia. 2002. Disponível em: < www.iceg.pucminas.br/espaco/revista/pdf/E\%20 $\& \% 20 \mathrm{G} \% 20 \mathrm{n} \% 206 \% 20 \mathrm{art} \% 2003$.pdf>. Acesso em: 10 dez. 2007.

PORTER, M. E. Competitive strategy: techniques for analyzing industries and competitors. 4th ed. New York: Free Press, 1980.

PORTER, M. Vantagem competitiva: criando e sustentando um desempenho superior. 4. ed. Rio de Janeiro: Campus, 1989.

PRAHALAD, C. K.; HAMEL, G. The core competencies of the corporation. Harvard Business Review, v. 68, n. 3, p. 88-101, 1990.

ROSA, L. C. Contribuição metodológica para análise estrutural de sistemas agroindustriais: um estudo do segmento produtor de vinhos finos do Rio Grande do Sul. 2001. 220 f. Tese (Doutorado em Engenharia da Produção) - Universidade Federal de Santa Catarina, Florianópolis, 2001.

SCORVO FILHO, J. D.; MARTIN, N. B.; AYROSA, L. M. S. Piscicultura em São Paulo: custos e retornos de diferentes sistemas de produção na safra 1996/97. Informações Econômicas, São Paulo, v. 28, n. 7, p. 41 60, 1998.

SHANK, J. K.; GOVINDARAJAN, V. A revolução dos custos. 4. ed. Rio de Janeiro: Campus, 1997.

Recebido: 30/08/2010 Received: 08/30/2010

Aprovado: $12 / 11 / 2010$ Approved: 11/12/2010 